\title{
Nuclear export inhibitor leptomycin B induces the appearance of novel forms of human Mdm2 protein
}

\author{
S Menéndez',2, M Higgins',2, RG Berkson', C Edling', DP Lane' and S Laín*,' \\ 'Department of Surgery and Molecular Oncology, Ninewells Hospital and Medical School, Dundee DDI 9SY, UK
}

\begin{abstract}
The nuclear export inhibitor leptomycin B (LMB) prevents the export of proteins from the nucleus to the cytoplasm, protects p53 from Mdm2-mediated degradation and is a very potent inducer of the p53 transcriptional activity. Here we suggest that LMB can also interfere with the degradation of human Mdm2. In the presence of this drug, we observed two novel forms of this protein: a slow mobility form and an amino-terminal fragment with an apparent molecular mass of $32 \mathrm{kDa}$. The presence of this $32 \mathrm{kDa}$ band is abolished with proteasome inhibitors, indicating that its appearance could be because of limited processing by the proteasome. These results may be useful in understanding the mechanism of degradation of Mdm2 by the proteasome.

British Journal of Cancer (2003) 88, 636-643. doi:I0.1038/sj.bjc.6600752 www.bjcancer.com

(C) 2003 Cancer Research UK
\end{abstract}

Keywords: leptomycin B; human Mdm2; p53; proteasome; limited proteolysis

It is well established that approximately $50 \%$ of human tumours carry inactivating mutations in the p53 gene (reviewed in Hollstein et al, 1999). In many others, the p53 tumour suppressor function is hampered by the overexpression or inactivation of cellular factors that regulate the levels and activity of p53 or by the expression of certain oncoviral proteins (reviewed in Lane and Lain, 2002; Vousden, 2002). Radiotherapy and many of the chemotherapeutic drugs currently used in cancer treatment are potent inducers of the p53 response. Furthermore, a lack of response to these treatments has been frequently associated with mutations in the p53 gene (Pirollo et al, 2000; Soussi, 2000). These observations suggest that the activation of p53 is a key determinant for the success of a treatment. However, although effective in many cases, most of the available treatments have a serious disadvantage, namely their DNA-damaging effects, which in the long term may lead to the appearance of secondary tumours. Therefore, the search for novel nongenotoxic activators of the p53 response is widely thought to be essential in improving the treatment of those cancers in which the p53 function is not abolished by mutation.

We have previously shown that the Streptomyces sp. metabolite leptomycin $\mathrm{B}(\mathrm{LMB})$ induces the transcriptional activity of a p53dependent reporter plasmid (Lain et al, 1999a). This effect of LMB is accompanied by an increase in the levels of the products of two p53-dependent genes, $p 21$ and $M d m 2$ (Freedman and Levine, 1998; Lain et al, 1999a) in a p53-dependent manner (Smart et al, 1999). As presented here, the increase in the levels of these proteins is accompanied by an increase in the levels of their messenger RNAs (Figure 1A), firmly establishing that LMB induces the transcriptional activity of p53 and that this occurs without an increase in the levels of p53 mRNA expression (Figure 1B). We also show that

*Correspondence: Dr S Laín; E-mail: s.lain@dundee.ac.uk

${ }^{2}$ Contributed equally to this work

Received 18 September 2002; revised 4 November 2002; accepted 8 November 2002 the induction of a p53 reporter construct can occur at less than nanomolar concentrations of LMB (Figure 1B), demonstrating the potency of LMB as an inducer of the p53-dependent transcriptional activity.

Accordingly, we have previously reported that LMB has a strong killing effect on cell lines derived from neuroblastomas at nanomolar concentrations in a p53-dependent way, whereas it has only a relatively mild and reversible growth arresting effect on normal human fibroblasts in culture at micromolar concentrations (Smart et al, 1999).

In the early reports, LMB was shown to have antitumour effects in mouse xenograft models (Roberts et al, 1986) that led to a phase I trial (Newlands et al, 1996). Unfortunately, these studies had to be stopped because of the malaise and anorexia induced by the drug when administered systemically by intravenous injection. We then thought that LMB may be of use in the prevention of tumours, such as HPV-associated cervical carcinomas, that can be treated locally and that tend to be recurrent after surgery. This drug increased the stability and the transcriptional activity of p53 in cell lines derived from cervical cancers and effectively induced cell death in a p53-dependent way (Hietanen et al, 2000).

These results, together with the potency of LMB in inducing the transcriptional activity of $\mathrm{p} 53$, imply that the elucidation of the mechanism of action of LMB is of great importance, and may make it possible to define new ways to target the p53 pathway that yield effective nongenotoxic drugs.

LMB is thought to function primarily as an inhibitor of the export of proteins from the nucleus to the cytoplasm because of its ability to interact with and impair the function of the nuclear export factor crm-1 (Kudo et al, 1999). Although other effects of LMB that could lead to a DNA damage response cannot be excluded, LMB is likely to be a very potent inducer of the p53 response, which does not act directly through the DNA damage pathway (Lain et al, 1999b).

Middeler et al (1997) have elegantly demonstrated that p53 shuttles from the nucleus to the cytoplasm. Additionally, p53 was 
A

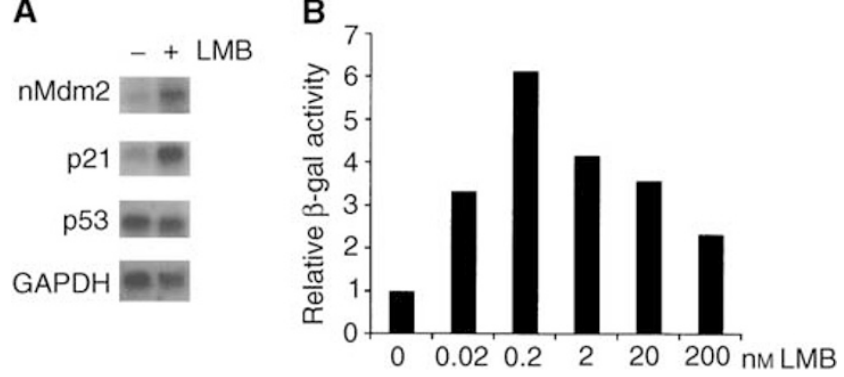

Figure I (A) LMB increases the levels of Mdm2 and p2I mRNAs. Total RNA was prepared from untreated or LMB-treated human normal primary fibroblasts and the hMdm2, p2I and p53 mRNAs were detected by Northern blotting. GAPDH mRNA was analysed as a control. (B) T22 RGC $\Delta$ fos-lac $Z$ cells were treated with the indicated concentrations of LMB for $18 \mathrm{~h}$ and $\mathrm{p} 53$-dependent $\beta$-gal reporter activity was measured.

shown to contain two nuclear export sequences, one in its oligomerisation domain (Stommel et al, 1999) and the other in its N-terminus (Zhang and Xiong, 2001), which probably explains its sensitivity to LMB. Direct interaction of p53 with crm-1 has not been reported yet.

In normal nonstressed cells, p53 has a very short half-life because of the following autoregulatory feedback loop mechanism in which the $\mathrm{Mdm} 2$ protein plays a key role. It has been well established that wild-type p53 acts as a transcriptional activator of the Mdm2 gene (Barak et al, 1993). In turn, Mdm2, which itself has a very short half-life because of its autoubiquitination activity (Fang et al, 2000), has the ability to interact with p53 and to function as an E3 ubiquitin ligase that promotes the conjugation of p53 to ubiquitin (Honda et al, 1997; Fang et al, 2000; Honda and Yasuda, 2000). This conjugation serves as a tag that effectively targets p53 for degradation by the proteasome (Haupt et al, 1997; Kubbutat et al, 1997). We have previously shown that LMB protects p53 from Mdm2-mediated ubiquitination and degradation (Lain et al, 1999a; Xirodimas et al, 2001b). Here, we have asked whether LMB has any effects on Mdm2.

\section{MATERIALS AND METHODS}

\section{Cells and culture conditions}

U2OS cells (expressing wild-type p53) and H1299 cells (p53negative) were obtained from the ATCC. The T22 RGC $\Delta$ fos-lac Z cell line and the human normal primary fibroblasts (HNF) were described in Lu et al (1996) and Lain et al (1999a), respectively. Cells were cultured in RPMI (H1299) or DMEM (U2OS, T22 $\Delta$ foslac $\mathrm{Z}$ and HNF) supplemented with $10 \%$ foetal calf serum and gentamycin antibiotic at $37^{\circ} \mathrm{C}$ in an atmosphere containing $5 \%$ $\mathrm{CO}_{2}$.

\section{Chemicals and reagents}

Leptomycin B was obtained from Novartis. Actinomycin D was obtained from Sigma. Stock solutions were prepared in absolute ethanol. Proteasome inhibitors (MG132, lactacystin, ALLN, epoxomycin and PI-II) and calpain inhibitors (ALLM and Z-Val-Phe$\mathrm{CHO}$ ) were obtained from Calbiochem, and stock solutions were prepared in DMSO.

\section{Plasmids}

pCMVhMdm2 and pCMVhMdm2 mtNLS were a kind gift from Dr A Levine. hMdm2 mtNoLS and the expression vector for p14ARF (pcDNA3p14ARF) were provided by K Vousden. pcDNA3Mdm2 $(1-244)$ and pcDNA3Mdm2 $(1-258)$ were described by Midgley et al (2000). pCMVhMdm2C462A as well as all other point mutants of $\mathrm{hMdm} 2$ were obtained by site-directed mutagenesis. The expression vector for the $\mathrm{N}$-terminal fragment of $\mathrm{hMdm} 2$ (pCMVhMdm2(1-244)) was derived from pCMVhMdm2 by insertion of a translation terminator at codon 245. pCOCMdm $2 \times 2$ was a gift from M Oren. pcDNA3p53 is described in Xirodimas et al (2001a). pSVp14ARF was obtained by inserting the NcoI-XbaI fragment of pcDNA3p14ARF into the SacI and XbaI sites of the $\mathrm{pSV}$ vector.

\section{Antibodies}

p53 was detected using the DO1 mouse monoclonal antibody (Stephen et al, 1995). Human Mdm2 was detected using the 4B2, 3G5, SMP14, 2A9, 2A10 and 4B11 mouse monoclonal antibodies (Chen et al, 1993; Picksley et al, 1994).

\section{Northern and $\beta$-gal reporter assays}

Total RNA was obtained from normal human primary fibroblasts and mRNA levels were analysed as described by Hietanen et al (2000).

T22RGC $\Delta$ fos-lac $Z$ cells were seeded at a density of $10^{4}$ cells per well in 96-well plates. After $24 \mathrm{~h}$ recovery time, LMB or control drugs were added and cells were incubated with the drugs for $16 \mathrm{~h}$. Cells were lysed in Promega reporter lysis buffer for $1 \mathrm{~h}$, and then incubated with CPRG $\beta$-gal substrate (Boehringer-Mannheim, Ingelheim, Germany). Colour density was measured at $590 \mathrm{~nm}$ using a Dynatech plate reader.

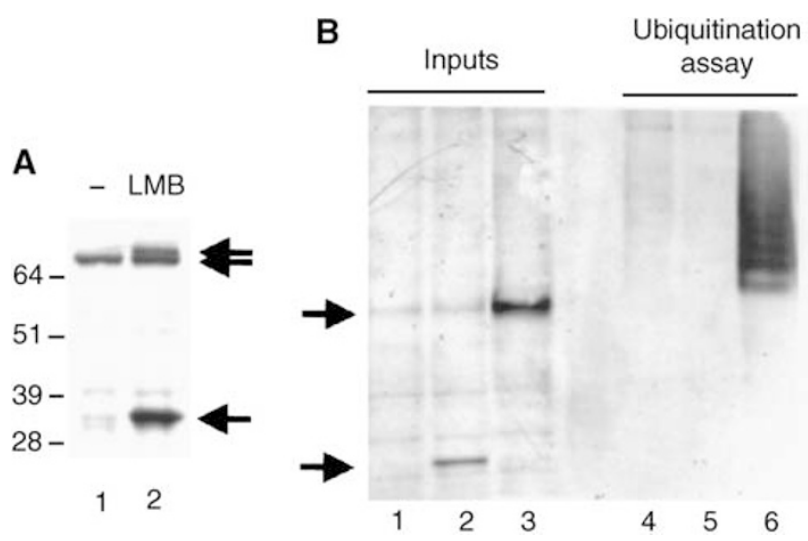

Figure 2 LMB induces the appearance of novel forms of hMdm2. (A) HI299 cells were transfected with an expression vector for hMdm2 (pCMVhMdm2) and left untreated (lane I) or treated with 2 nM LMB for $18 \mathrm{~h}$ (lane 2). Cell extracts were analysed by Western blotting and hMdm2 was detected using the 4B2 mouse monoclonal antibody against the aminoterminus of the protein. The positions of the bands corresponding to the full-length $\mathrm{hMdm} 2$, the LMB-induced slower mobility form and the $32 \mathrm{kDa}$ fragment are indicated by arrows. (B) LMB does not affect hMdm2 ubiquitination in vivo. HI 299 cells were transfected with $5 \mu \mathrm{g} \mathrm{pCMVhMdm2}$ and $2 \mu \mathrm{g}$ pCMVHis ${ }_{6}-U b i q u i t i n$. In lanes I and 3, cells were left untreated, in lanes 2 and 4 they were treated with $2 \mathrm{nM} \mathrm{LMB}$ and in lanes 3 and 6 , they were also cotransfected with $5 \mu \mathrm{g}$ of the pCDNA3p I4ARF expression vector. In lanes I-3, total hMdm2 was analysed and in lanes 4-6, His 6 ubiquitin complexes were isolated and ubiquitinated $\mathrm{hMdm} 2$ was detected using 4B2. 
U2OS cells were seeded in 24-well plates and transfected with $60 \mathrm{ng}$ of the RGC $\Delta$ Fos-lacZ p53 reporter plasmid, $60 \mathrm{ng}$ of the control SV-promoter-dependent luciferase reporter and the indicated plasmids expressing hMdm2(1-244) or p14ARF using the Fugene protocol as described by Midgley et al (2000). Cells were harvested $48 \mathrm{~h}$ after transfection. $\beta$-gal activity was measured as above and luciferase activity was analysed using the Dual-Luciferase ${ }^{\circledR} \quad$ Reporter Assay System (Promega, Southampton, UK), a MicroLumat LB96 V(EG\&G Berthold) luminometer.

\section{Western blot analysis}

Cells were seeded in $10 \mathrm{~cm}$ dishes at a density of $9 \times 10^{5}$ cells per well and transfected using the calcium phosphate method. Equivalent amounts of CMV promoter in the transfections were maintained with the pcDNA3 control vector. The amount of plasmid used in each transfection was topped up to $20 \mu \mathrm{g}$ with the bacterial plasmid Bluescript. After a $24 \mathrm{~h}$ recovery period, $2 \mathrm{nM} \mathrm{LMB}$ and the indicated amounts of proteasome inhibitors were added to the cells for $18 \mathrm{~h}$ before harvesting. Cell lysates were prepared using the NP40 buffer described by Xirodimas et al (2001a) or by direct lysis in SDS PAGE loading buffer. Equivalent results were obtained with both the methods. Samples were analysed in $4-12 \%$ Novex gels using
MOPS running buffer after which they were transferred to Immobilon membranes that were incubated with the indicated primary antibodies and developed as described by Xirodimas et al (2001a).

\section{Purification of His-tagged ubiquitin conjugates}

For the in vivo ubiquitination assay, vectors expressing the relevant proteins were cotransfected with $2 \mu \mathrm{g}$ of the vector encoding His-tagged ubiquitin. Purification of $\mathrm{His}_{6}$-ubiquitinated conjugates was performed as described in Xirodimas et al (2001a). His-ubiquitin tagged hMdm2 was analysed by Western blot analysis with $4 \mathrm{~B} 2$ antibody.

\section{RESULTS}

\section{LMB induces the appearance of two novel forms of hMdm2}

Mdm2 has been described to shuttle between the nucleus and the cytoplasm and to contain a crm1-binding nuclear export sequence (Roth et al, 1998). Accordingly, Argentini et al (2001) found that LMB partly decreases the export of Mdm2 from the nucleus using heterokaryon assays. However, this is not reflected by any convincing changes in the localisation of $\mathrm{Mdm} 2$ in the presence
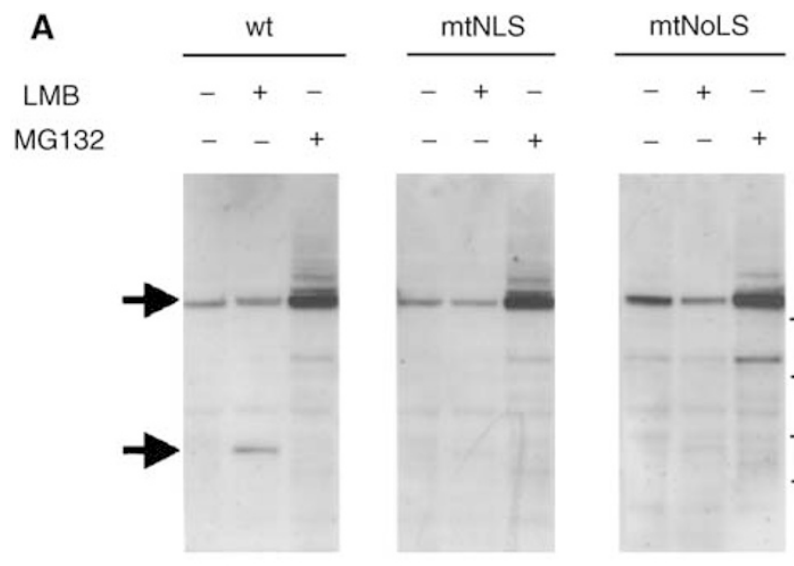
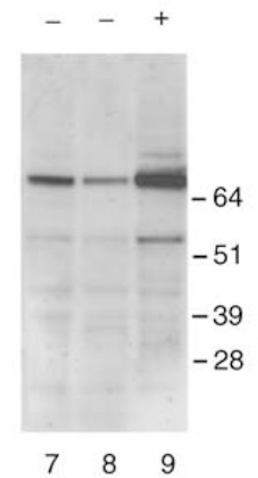

$\begin{array}{lll}7 & 8 & 9\end{array}$

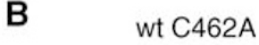

B
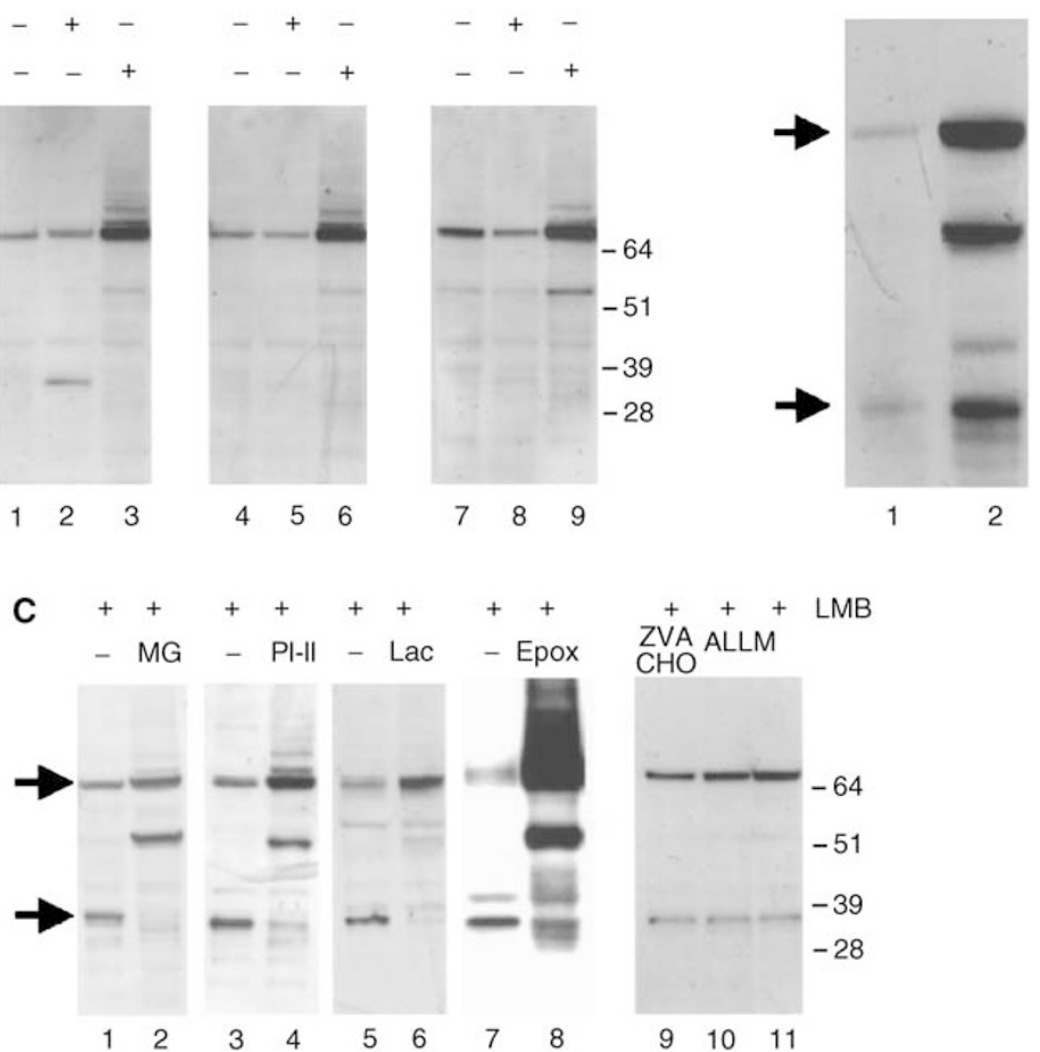

Figure 3 The appearance of the $32 \mathrm{kDa}$ is a post-transcriptional event and is prevented by proteasome inhibitors. (A) HI 299 cells were transfected with vectors expressing either wild-type hMdm2 lanes (I-3), hMdm2 mtNLS lanes (4-6) or hMdm2mtNoLS lanes (7-9). In lanes I, 4 and 7, cells were left untreated. In lanes 2, 5 and 8, they were treated with LMB, in lanes 3, 6 and 9, they were treated for $3 \mathrm{~h}$ with the proteasome inhibitor MG I 32 (20 $\mu$ M). Cells were harvested and $\mathrm{hMdm} 2$ was detected by Western blotting as above. The positions of the bands corresponding to the full-length $\mathrm{hMdm} 2 \mathrm{and}$ the $32 \mathrm{kDa}$ fragment are indicated by arrows. (B) HI299 cells were transfected with an expression vector for hMdm2 or the hMdm2C462A mutant and treated with $2 \mathrm{nM}$ leptomycin B for $18 \mathrm{~h}$. hMdm2 was detected as above. (C) HI299 cells were transfected with $5 \mu \mathrm{g}$ of the expression vector for hMdm2 (pCMVhMdm2) and treated with $2 \mathrm{nM}$ leptomycin B alone for $18 \mathrm{~h}$ (lanes I, 3, 5, 7 and II) or together with $20 \mu \mathrm{M} \mathrm{MGI32} \mathrm{(lane} \mathrm{2),} 20 \mu \mathrm{M}$ PI-II (lane 4) or $20 \mu \mathrm{M}$ lactacystin (lane 6), $4 \mu \mathrm{M}$ epoxomycin (lane 8), $10 \mu \mathrm{M}$ Z-Val-Phe-CHO (lane 9) or $10 \mu \mathrm{M}$ ALLM (lane 10). Cell extracts were analysed by Western blotting and $\mathrm{hMdm} 2$ was detected using 4B2. The positions of the bands corresponding to the full-length hMdm2 and the $32 \mathrm{kDa}$ fragment are indicated by arrows on the left side. 
of LMB by either immunocytofluorescence or cell fractionation experiments (data not shown). Instead, we observed that LMB induces the appearance of a shorter human Mdm2 (hMdm2) product of approximately $32 \mathrm{kDa}$, which reacts with the $4 \mathrm{~B} 2$ mouse monoclonal antibody directed against the amino terminus of the protein (Chen et al, 1993). Other insults that are known to activate p53, such as actinomycin D and UVC, did not cause the appearance of this product (not shown). In many experiments, we could also detect that the presence of the $32 \mathrm{kDa}$ band is accompanied by the appearance of another modified form of hMdm2 with a slightly slower electrophoretic mobility than fulllength $\mathrm{hMdm} 2$ in nontreated cells. As shown in the in vivo ubiquitination assay presented in Figure $2 \mathrm{~B}$, unlike proteasome inhibitors and the p14ARF tumour suppressor (Xirodimas et al, 2001a), LMB did not increase the levels of ubiquitin-conjugated hMdm2 and the $32 \mathrm{kDa}$ band did not appear to be bound to ubiquitin.

\section{The appearance of the $32 \mathrm{kDa}$ band in the presence of LMB is suppressed by proteasome inhibitors}

As shown in Figure 3A, LMB did not effectively induce the appearance of the $32 \mathrm{kDa}$ band in cells transfected with a human Mdm2 with mutations in its nuclear localisation signal at residues 181-185 (hMdm2 mtNLS) (Tao and Levine, 1999), or in its nucleolar localisation signal ( $\mathrm{hMdm} 2 \mathrm{mtNoLS})$ that is located between residues 466 and 473 (Lohrum et al, 2000). This result has two consequences. First, it establishes that the appearance of the $32 \mathrm{kDa}$ band is due to an effect on the Mdm2 protein and not to an effect of LMB on the expression of the transfected vector. Second, it could suggest that the appearance of the $32 \mathrm{kDa}$ band requires that hMdm2 reaches the nuclear and nucleolar comparments efficiently.

In subsequent experiments, we aimed to characterise the activity responsible for the accumulation of the $32 \mathrm{kDa}$ band in the presence of LMB. Mdm2 has been previously described to be susceptible to caspase cleavage, producing a band of approximately $60 \mathrm{kDa}$ (Pochampally et al, 1999). However, the levels of the $32 \mathrm{kDa}$ band detected with LMB were not decreased by preincubation with caspase inhibitors (not shown). Instead, we observed that the ratio between the levels of full-length hMdm2 and the $32 \mathrm{kDa}$ product significantly decreased when an hMdm2 variant with a point mutation in its RING finger domain (hMdm2C462A), and therefore deficient for autoubiquitination and degradation (Honda et al, 1997), was analysed (Figure 3B). This suggested that the appearance of the $32 \mathrm{kDa}$ fragment could be to some extent dependent on ubiquitination status of $\mathrm{Mdm} 2$ and therefore, potentially because of a proteasome-associated proteolytic activity.

As presented in Figure 3C (lanes 2 and 4), the proteasome inhibitors MG132 and PI-II (Z-LeuLeuPhe-CHO) significantly decreased the appearance of the $32 \mathrm{kDa}$ fragment in the presence of LMB. This effect is also observed with the more specific inhibitors of the proteasome activity lactacystin and epoxomycin (Figure 3C, lanes 6 and 8), but not with the calpain inhibitors ZVal-Phe-CHO and ALLM (Figure 3C, lanes 9 and 10). These results suggest that the appearance of the $32 \mathrm{kDa}$ fragment may depend on the activity of the proteasome. The band that appears below the $64 \mathrm{kDa}$ marker after long-term incubation with proteasome inhibitors (Figure 3C) and with the hMdm2C462A mutant (Figure $3 \mathrm{~B}$ ) could be related to the caspase-dependent cleavage (Pochampally et al, 1999).

The cleavage did not seem to be because of an induction of a proteolytic activity, since the presence of the $32 \mathrm{kDa}$ fragment was never accompanied by a decrease in the levels of full-length hMdm2 (Figure 2A, B, 3A, and 5A, B). This suggested that LMB could increase the stability of this fragment. However, we observed that the $32 \mathrm{kDa}$ band is very stable (Figure $4 \mathrm{~A}, \mathrm{~B}$ ), and that it was
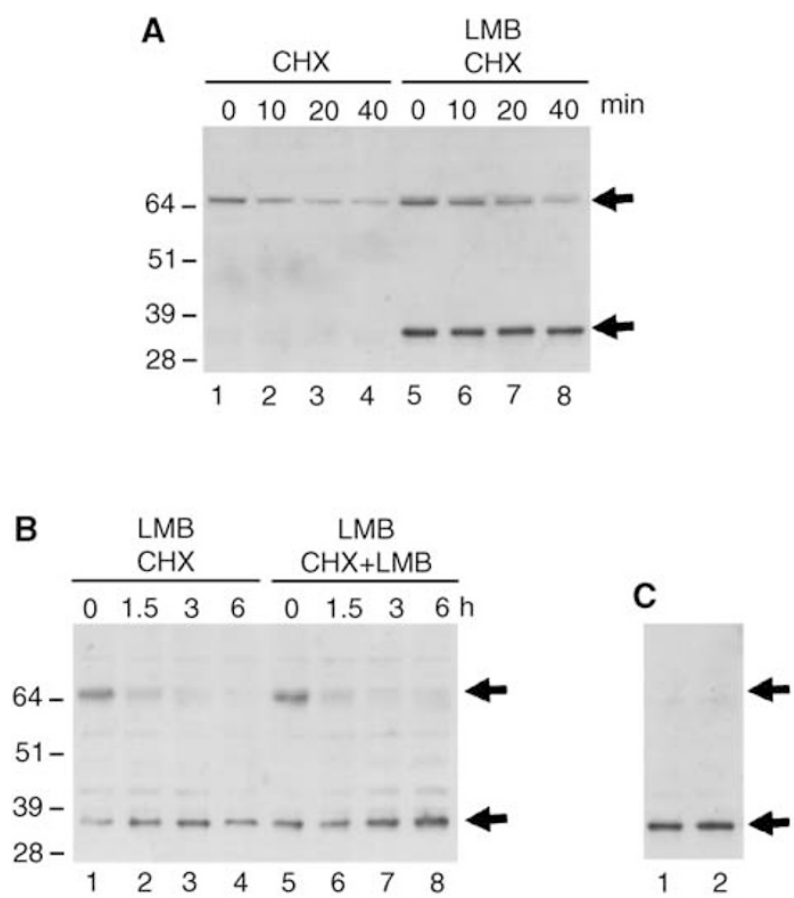

Figure 4 Analysis of the stability of hMdm2 in the presence of LMB. (A) HI299 cells were transfected with the expression vector for hMdm2 and left untreated (lanes I -4) or pretreated with 2 nM LMB for $18 \mathrm{~h}$ (lanes 58). After this time, $10 \mu \mathrm{g} \mathrm{ml}^{-1}$ cyclohexamide $(\mathrm{CHX})$ was added to the medium and the cells were harvested after 0, 10, 20 and $40 \mathrm{~min}$. Cell extracts were analysed by Western blotting and hMdm2 was detected using 4B2. The positions of the bands corresponding to the full-length hMdm2 and the $32 \mathrm{kDa}$ fragment are indicated by arrows. (B) HI 299 cells were transfected with the expression vector for $\mathrm{hMdm} 2$ and pretreated with $2 \mathrm{nM}$ LMB for $18 \mathrm{~h}$. After this time, the medium was removed and replaced with a medium containing $10 \mu \mathrm{gml} l^{-1} \mathrm{CHX}$ (lanes I-4) or a medium containing $\left.10 \mu \mathrm{g} \mathrm{m}\right|^{-1} \mathrm{CHX}$ and $2 \mathrm{nM} \mathrm{LMB}$ (lanes 5-8). Cells were harvested after $0,1.5,3$ and $6 \mathrm{~h}$ and cell extracts were analysed by Western blotting and hMdm2 was detected using 4B2. (C) HI299 cells were transfected with the expression vector for $\mathrm{hMdm} 2$ and pretreated with $2 \mathrm{nM} \mathrm{LMB}$ for $18 \mathrm{~h}$ after which $10 \mu \mathrm{g} \mathrm{ml} \mathrm{l}^{-1} \mathrm{CHX}$ was added for $4 \mathrm{~h}$. At this time, virtually all detected $\mathrm{hMdm} 2$ has an apparent molecular weight of $32 \mathrm{kDa}$. In order to see whether removal of LMB destabilised the $32 \mathrm{kDa}$ fragment, we removed the medium and replaced it with a medium containing $10 \mu \mathrm{g} \mathrm{ml}^{-1} \mathrm{CHX}$ only (lane I) or a medium containing $10 \mu \mathrm{g} \mathrm{ml}^{-1} \mathrm{CHX}$ and $2 \mathrm{nM} \mathrm{LMB}$ (lane 2). After 5 more $h$, cells were harvested and analysed as above.

not significantly destabilised after removal of LMB from the medium (Figure 4C).

\section{Mapping of the cleavage site generating the $\mathrm{N}$-terminal $32 \mathrm{kDa}$ fragment}

As shown in Figure $5 \mathrm{~A}$, the $32 \mathrm{kDa}$ fragment detected in the presence of LMB contains epitopes 4B2, 3G5, SMP14 and 2A9 reacting with the amino-terminal half of Mdm2 (Chen et al, 1993; Picksley et al, 1994). Instead, the $2 \mathrm{~A} 10$ and 4B11 antibodies, that react with the C-terminus of Mdm2 (Chen et al, 1993) do not recognise the $32 \mathrm{kDa}$ band (Figure $5 \mathrm{~B}$ ). We have not been able to find the $\mathrm{C}$-terminal fragment resulting from this cleavage with any of these two antibodies. Several additional bands were obtained with the C-terminal antibodies $2 \mathrm{~A} 10$ and $4 \mathrm{~B} 11$ (Figure 5B); however, these bands also appear in cells not overexpressing hMdm2 (not shown) and independent of the presence of LMB (Figure 5B). 


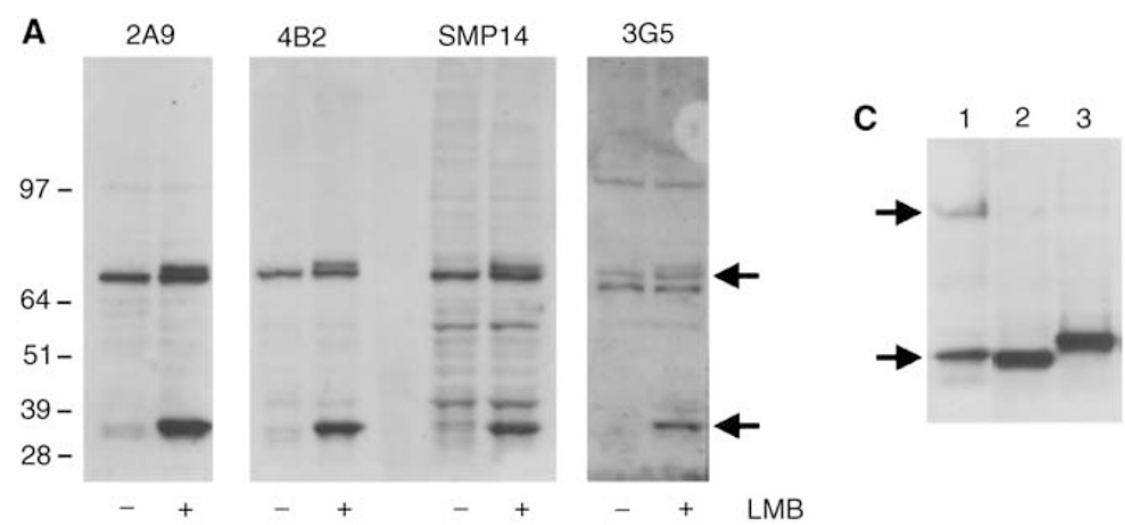

B
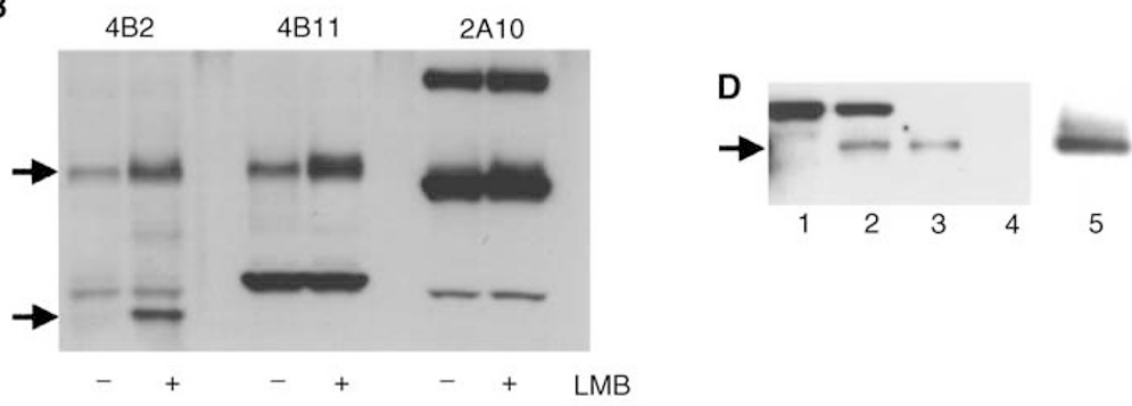

E

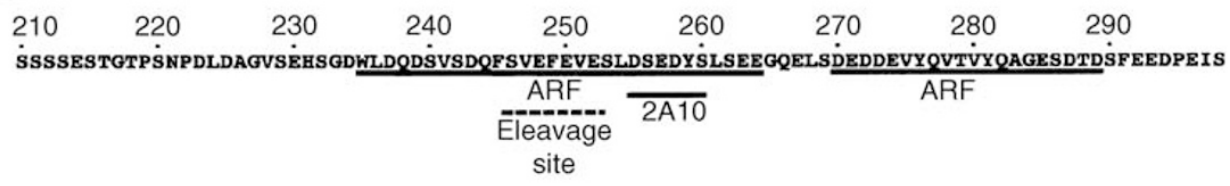

Figure 5 Mapping of the $32 \mathrm{kDa}$ band C-terminal region. (A and B) HI 299 cells were transfected with an expression vector for hMdm2 (pCMVhMdm2) and left untreated $(-)$ or treated with $2 \mathrm{nM} \mathrm{LMB}$ for $18 \mathrm{~h}(+)$. Cell extracts were analysed by Western blotting and hMdm2 was detected using the mouse monoclonal antibodies 2A9, 4B2, SMPI4 and 2A9 (A), or 4B2, 4BII and 2AI0. (B). The positions of the bands corresponding to the full-length hMdm2 and the $32 \mathrm{kDa}$ fragment are indicated by arrows. (C) HI299 cells were transfected with an expression vector for hMdm2 (pCMVhMdm2) (lanel), a vector expressing residues I-244 of murine Mdm2 (pcDNA3Mdm2 I-244) or a vector expressing residues I-258 (pcDNA3Mdm2 I-258) (lane3). pcDNA3Mdm2 I-244 and pcDNA3Mdm2 I-258 contain six and 14 additional residues at their C-terminus, respectively. (D) HI299 cells were transfected with expression vectors for hMdm2 $\left(\mathrm{I}-252 \mathrm{~N}_{47}\right.$ ) (lanes I and 2) or hMdm2 (lanes 3 and 4 ). In lanes 2 and 3, cells were treated with $2 \mathrm{nM} \mathrm{LMB} \mathrm{for}$ $18 \mathrm{~h}$. Cell extracts were analysed by Western blotting and developed with the 4B2 antibody. The position of the $32 \mathrm{kDa}$ band is indicated with an arrow. In lane 5, cells were transfected with the plasmid encoding the hMdm2 (I -244) mutant. This fragment is expressed at very high levels, and therefore, a shorter exposure of the gel is shown for this lane. (E) Sequence of the acidic domain in $\mathrm{hMdm} 2$. The regions involved in the interaction with the amino-terminus of p I4ARF according to Bothner et al (200I) and the 2AlO epitope are underlined. The region proposed to contain the C-terminus of the $32 \mathrm{kDa}$ band is marked with a discontinuous line.

Using a series of deletion mutants of murine Mdm2 (Midgley et al, 2000), we were able to roughly map the region containing the C-terminus of this $32 \mathrm{kDa}$ N-terminal fragment of $\mathrm{Mdm} 2$ (Figure 5C). According to this measurement, the C-terminus of this fragment is located approximately within amino 245 and 272 of human Mdm2. The 2A10 antibody has been shown to recognise two epitopes in Mdm2: one between positions 255 and 260, and a C-terminal epitope at positions 388 and 392. The lack of $2 \mathrm{~A} 10$ reactivity of the $32 \mathrm{kDa}$ fragment allowed us to map the C-terminus of the $32 \mathrm{kDa}$ fragment more accurately to a region between residues 245 to approximately 260 . Interestingly, this region is contained within a a region that is bound by the p14ARF tumour suppressor (Midgley et al, 2000; Bothner et al, 2001) (Figure 5E). However, we have not been able to show that p14ARF overexpression affects the levels of the $32 \mathrm{kDa}$ LMB-induced band (not shown).

We then proceeded to substitute the amino acids in this region by alanine using site-directed mutagenesis. Residues $245,246,247$, $248,249,250,251,252,253,254,255,256,259,260$ and 261 were substituted. Despite our efforts, we have not been able to identify a specific residue required for this cleavage event. However, a fortuitous mutation allowed us to map the cleavage site more accurately. When introducing a point mutation at position 254 , an open reading frame encoding a frame shift mutant of hMdm2 was obtained. This mutant finished at position 252 of the hMdm2 sequence and had 47 extra residues at its C-terminus encoded by an alternative reading frame $\left(\mathrm{hMdm} 2\left(1-252 \mathrm{~N}_{47}\right)\right)$. When cells expressing this mutant were treated with LMB, the $32 \mathrm{kDa}$ band still appeared (Figure 5D). This indicates that the C-terminus of the $32 \mathrm{kDa}$ band is before or at position 252 .

\section{An N-terminal fragment consisting of residues 1-244 from hMdm2 can protect p53 from degradation by Mdm2}

To study the significance of this $32 \mathrm{kDa}$ fragment for p53 stabilisation and activity, we created an expression vector for an hMdm2 deletion mutant that contains the first 244 amino acids 
from the N-terminus (pCMVhMdm2(1-244)) (Figure 5D, lane 5). This deletion mutant was able to protect $\mathrm{p} 53$ from degradation by full-length murine Mdm2 (Figure 6A), possibly by competing with $\mathrm{Mdm} 2$ for its interaction with p53. This fragment of hMdm2 contains the region necessary for binding to p53 and binding of $\mathrm{Mdm} 2$ to $\mathrm{p} 53$ is thought to be sufficient to inactivate the transcriptional activity of $\mathrm{p} 53$ (Chen et al, 1996). Therefore, as could be expected, this deletion mutant could not induce the transcriptional activity of p53 (Figure 6B). This lack of activation was not because of a toxic effect of the pCMVhMdm2 $(1-244)$ vector as indicated by the analysis of the control luciferase reporter activity, where hMdm2 (1-244) expression significantly increases this activity.

\section{DISCUSSION}

We have shown that the electrophoretic behaviour of hMdm2 is altered significantly in the presence of the nuclear export inhibitor LMB. LMB induces the appearance of two novel hMdm2 products, namely a band migrating slightly slower than the major hMdm2 band in the absence of drug, and a product with an apparent molecular weight of $32 \mathrm{kDa}$, containing epitopes from the $\mathrm{N}$ terminal part of hMdm2. The C-terminus of this fragment maps between residues 245 and 252 of hMdm2.

The $32 \mathrm{kDa} \mathrm{N}$-terminal fragment of hMdm2 may have some relevance for the observed stabilisation of p53 by LMB as evidenced by the ability of transfected truncated hMdm2 to protect p53 from Mdm2-mediated degradation, possibly by acting as a dominant negative towards Mdm2. However, although LMB protects p53 from murine Mdm2-mediated ubiquitination and degradation (Xirodimas et al, 2001b), the corresponding $32 \mathrm{kDa}$ form of murine Mdm2 has never been detected. Therefore, although the accumulation of the $32 \mathrm{kDa}$ fragment may contribute to the stabilisation of $\mathrm{p} 53$ by $\mathrm{LMB}$, it is not indispensable. Additionally, the induction of the accumulation of the $32 \mathrm{kDa}$ cleavage product of hMdm2 is not likely to contribute to the potent activation of p53-dependent transcription by LMB, since a similar fragment does not increase, but rather decreases, p53 activity in a transcriptional reporter system. One possibility is that the accumulation of the $32 \mathrm{kDa}$ fragment negatively modulates the p53 transcriptional activity and contributes to diminishing the cytotoxic effects of LMB.

The appearance of the $32 \mathrm{kDa}$ fragment occurs without significant decrease in the level of full-length hMdm2. However, this does not seem to be because of alterations in the expression of ectopic hMdm2 cDNA, since different small mutations at distant sites of the protein (the NLS and the NoLS) prevent the detection of the $32 \mathrm{kDa}$ band. The levels of the $32 \mathrm{kDa}$ band did not seem to be related to the nuclear export signal in hMdm2 proposed by Roth et al (1998), since this band also appeared when cells transfected with a mutant for this putative nuclear export signal were treated with LMB (not shown).

Inhibition of crm1-mediated nuclear export by LMB could alter some event in the degradation of $\mathrm{hMdm} 2$ by the proteasome, allowing an amino-terminal product to accumulate when it would not otherwise do so. Supporting this hypothesis, we have shown that the appearance of the $32 \mathrm{kDa}$ band is clearly prevented by several proteasome inhibitors. Although it is possible that proteasome inhibitors, and even lactacystin, may be affecting other proteolytic activities in addition to that of the proteasome (Ostrowska et al, 2000), given the diversity of proteasome inhibitors having the same effect, it is unlikely that the appearance of the $32 \mathrm{kDa}$ fragment is not because of limited proteolysis by the proteasome.

We have shown that the $32 \mathrm{kDa}$ band corresponds to the aminoterminal half of the protein and we have determined that the Cterminus of the $32 \mathrm{kDa}$ band lies within residues 245 to
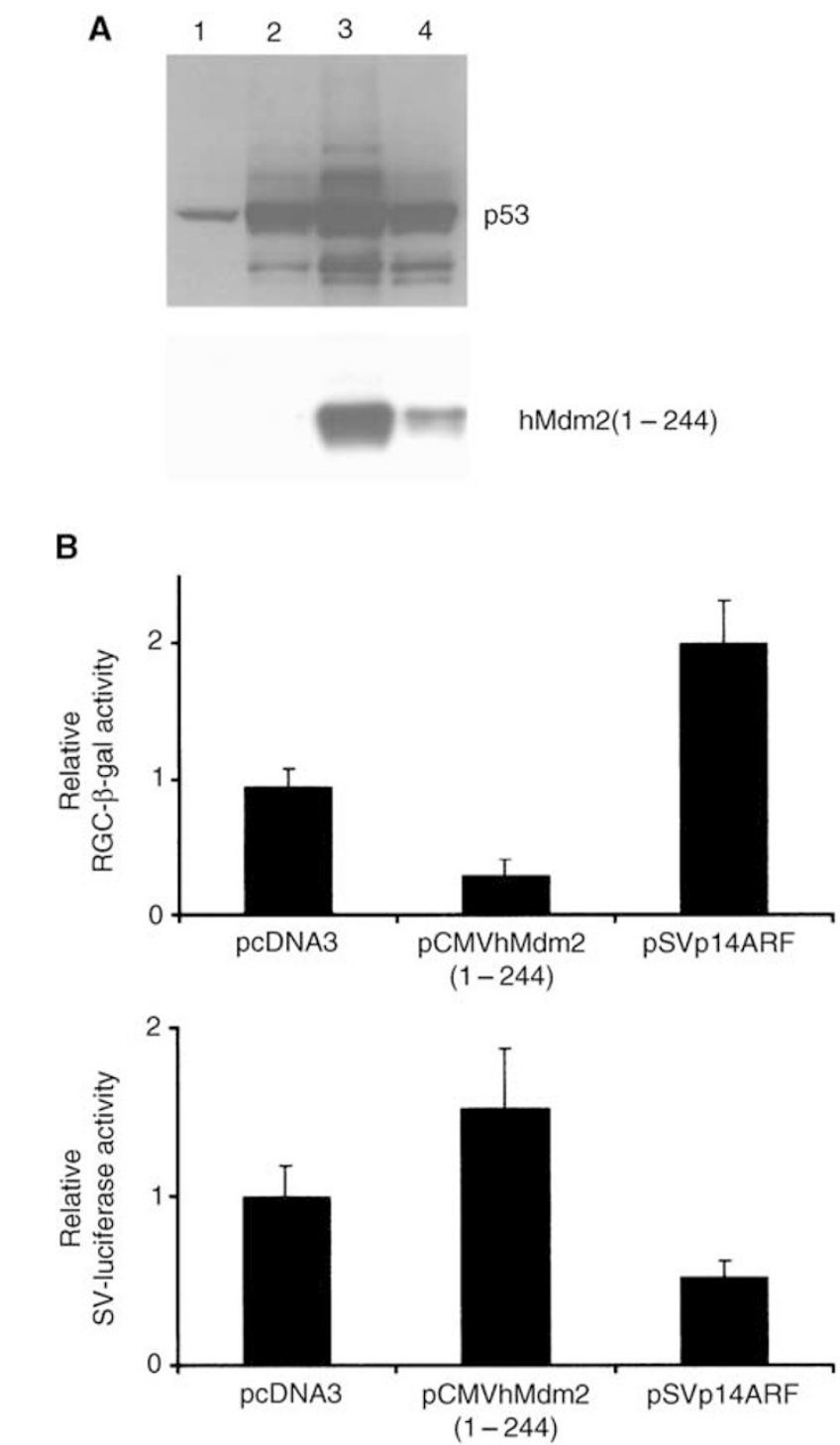

Figure 6 The $1-244$ fragment of hMdm2 protects p53 from Mdm2mediated degradation, but does not increase the transcriptional activity of p53. (A) H1299 cells were transfected as described with $2 \mu \mathrm{g}$ of pcDNA3p53 and $2 \mu \mathrm{g}$ of pCOCMdm2 $\times 2$ (lane I), $2 \mu \mathrm{g}$ of pcDNA3p53 (lane 2), $2 \mu \mathrm{g}$ of pCDNA3p53, $2 \mu \mathrm{g}$ of pCOCMdm2 $\times 2$ and $15 \mu \mathrm{g}$ of pCMVhMdm2 (I-244) (lane 3), or $2 \mu \mathrm{g}$ of pcDNA3p53, $2 \mu \mathrm{g}$ of pCOCMdm2 22 and $7.5 \mu \mathrm{g}$ of PCMVhMdm2 (I-244) I $\mu \mathrm{g}$ (lane 4). Cells were analysed by Western blotting using the DOI antibody against p53 (upper panel). hMdm2 (I - 244) was detected using the 4B2 antibody against Mdm2 (lower panel). (B) U2OS cells, which contain endogenous wild-type p53, were transfected with the p53-dependent RGC $\Delta$ Fos-lacZ and the SV-luciferase reporter plasmids together with either $0.25 \mu \mathrm{g}$ pcDNA3 control vector, $0.25 \mu \mathrm{g}$ pCMVhMdm2 (I-244) or $0.025 \mu \mathrm{g}$ pSVp I 4ARF. p53-dependent $\beta$-gal and control SV40 early promoter-driven luciferase reporter activities were measured. The average and the s.d. of four transfections with each set of constructs is shown.

approximately 252 of the hMdm2 sequence. However, extensive point mutagenesis of this region did not abolish the proteolytic event. It is interesting to note that in the case of the $\mathrm{NF} \kappa \mathrm{B}$ p105 precursor, which is known to be susceptible to partial proteasome-mediated proteolysis to generate the p50 active fragment (Palombella et al, 1994), it has not been possible to precisely map the cleavage site. This indicates that the cleavage of hMdm2 and p105 are not sequence dependent, but may rely on recognition of a structural feature. In the case of 
$N F \kappa B$, a glycine-rich region (GRR) between positions 375 and 401 has been shown to be involved in the generation of the p50 form that is thought to occur at approximately position 433 (Lin and Ghosh, 1996). No similar GRR can be found in the hMdm2 sequence.

The cleavage site that would generate the $32 \mathrm{kDa}$ band maps to a conserved and unstructured region in hMdm2 rich in acidic residues and serines (Bothner et al, 2001). There is also data showing that this acidic domain is important for the stability of Mdm2. As reported by Argentini et al (2001), deletion of the acidic domain (residues 222-272) increases the stability of the protein without decreasing its ubiquitination. Additionally, the interaction site for the amino terminus of p14ARF, which is necessary for p14ARF to increase the levels of Mdm2 and its ubiquitinated forms (Xirodimas et al, 2001a), is also in this acidic region (Midgley et al, 2000; Bothner et al, 2001). PEST sequences are conformationally flexible regions that do not show a high conservation of exact sequence, but contain a high proportion of proline $(\mathrm{P})$, glutamate $(\mathrm{E})$, serine (S) and threonine $(\mathrm{T})$. This type of sequence is considered to target proteins for degradation by the proteasome and possibly other proteolytic systems (Rechsteiner and Rogers, 1996). The importance of the acidic domain for Mdm2 stability and the data presented here could suggest that the acidic region of $\mathrm{Mdm} 2$ may act as a PEST sequence.

The C-terminal fragment generated from the limited proteolysis of the p105 precursor of $N F \kappa B$ has not been detected and there is a lack of precursor-product relation between the p105 and p50 forms (Lin et al, 1998, 2000). This behaviour is also observed here for full-length hMdm2 and the $32 \mathrm{kDa}$ fragment. In the case of $N F \kappa B$, these phenomena have been proposed by some authors to be because of cotranslational processing of the protein during synthesis (Lin et al, 1998, 2000). This model is unlikely to be compatible with our observations since mutations near the $\mathrm{C}$ terminus of the protein (at the NoLS) impair the appearance of the $32 \mathrm{kDa}$ band.

Another way to explain our observations is that in normal conditions, hMdm2 undergoes a first proteasome-dependent cleavage within the acidic domain and that in the presence of the nuclear export inhibitor LMB, the N-terminal portion persists, while the $\mathrm{C}$-terminus is degraded. This lack of further degradation of the $\mathrm{N}$-terminal region when nuclear export is inhibited could be because of a direct effect of inhibition of nuclear export on the $32 \mathrm{kDa}$ fragment, which retains its nuclear export signal at positions 197-211 (Roth et al, 1998). However, we have not been able to see that the $32 \mathrm{kDa}$ fragment specifically accumulates in the nuclear compartment (unpublished data) and as mentioned before, the nuclear export mutant of hMdm2 behaves exactly as the wild-type. LMB could also have an effect on the activity or localisation of proteasomes. This is unlikely since we have shown that the full-length hMdm2 is still effectively degraded in LMBtreated cells and that the $32 \mathrm{kDa}$ fragment is very stable and does not seem to be further stabilised by LMB.

Alternatively, inhibition of nuclear export by LMB could induce a modification at the amino-terminal half of the full-length protein and this modification could prevent the amino $32 \mathrm{kDa}$ fragment of $\mathrm{hMdm} 2$ from complete degradation. This 'protective' modification may be related to the appearance of the slower migrating form of full-length $\mathrm{hMdm} 2$ with LMB. Interestingly, the PI3-kinase inhibitor LY294002 induces the accumulation of full-length $\mathrm{hMdm} 2$ and an apparently equivalent $\mathrm{N}$-terminal $32 \mathrm{kDa}$ fragment of $\mathrm{hMdm} 2$ to that seen with LMB (Menendez S, unpublished data).

In summary, the observations presented here on the effect of LMB on hMdm2 indicate that the degradation of hMdm2 could be a stepwise process and therefore it can be limited in particular circumstances.

\section{ACKNOWLEDGEMENTS}

We thank Dr A Levine, Dr K Vousden and Dr M Oren for the expression vectors and $\mathrm{N}$ Perkins and $\mathrm{M}$ Saville for a critical reading of the manuscript. Leptomycin $\mathrm{B}$ was a kind gift from Novartis. This work was supported by Cancer Research UK and Tenovus.

\section{REFERENCES}

Argentini M, Barboule N, Wasylyk B (2001) The contribution of the acidic domain of MDM2 to p53 and MDM2 stability. Oncogene 20: $1267-1275$

Barak Y, Juven T, Haffner R, Oren M (1993) mdm2 expression is induced by wildtype p53 activity. $E M B O J$ 12: $461-468$

Bothner B, Lewis WS, DiGiammarino EL, Weber JD, Bothner SJ, Kriwacki RW (2001) Defining the molecular basis of Arf and Hdm2 interactions. J Mol Biol 314: 263-277

Chen J, Marechal V, Levine AJ (1993) Mapping of the p53 and Mdm-2 interaction domains. Mol Cell Biol 13: 4107-4114

Chen J, Wu X, Lin J, Levine AJ (1996) mdm-2 inhibits the G1 arrest and apoptosis functions of the p53 tumor suppressor protein. Mol Cell Biol 16: $2445-2452$

Fang S, Jensen JP, Ludwig RL, Vousden KH, Weissman AM (2000) Mdm2 is a RING finger-dependent ubiquitin protein ligase for itself and p53. J Biol Chem 275: $8945-8951$

Freedman DA, Levine AJ (1998) Nuclear export is required for degradation of endogenous p53 by MDM2 and human papillomavirus E6. Mol Cell Biol 18: $7288-7293$

Haupt Y, Maya R, Kazaz A, Oren M (1997) Mdm2 promotes the rapid degradation of p53. Nature 387: 296-299

Hietanen S, Lain S, Krausz E, Blattner C, Lane DP (2000) Activation of p53 in cervical carcinoma cells by small molecules. Proc Natl Acad Sci USA 97: $8501-8506$

Hollstein M, Hergenhahn M, Yang Q, Bartsch H, Wang ZQ, Hainaut P (1999) New approaches to understanding p53 gene tumor mutation spectra. Mutat Res 431: 199-209
Honda R, Tanaka H, Yasuda H (1997) Oncoprotein MDM2 is a ubiquitin ligase E3 for tumor suppressor p53. FEBS Lett 420: 25-27

Honda R, Yasuda H (2000) Activity of MDM2, a ubiquitin ligase, toward p53 or itself is dependent on the RING finger domain of the ligase. Oncogene 19: $1473-1476$

Kubbutat MH, Jones SN, Vousden KH (1997) Regulation of p53 stability by Mdm2. Nature 387: 299-303

Kudo N, Matsumori N, Taoka H, Fujiwara D, Schreiner EP, Wolff B, Yoshida M, Horinouchi S (1999) Leptomycin B inactivates CRM1/ exportin 1 by covalent modification at a cysteine residue in the central conserved region. Proc Natl Acad Sci USA 96: 9112-9117

Lain S, Midgley C, Sparks A, Lane EB, Lane DP (1999a) An inhibitor of nuclear export activates the p53 response and induces the localization of HDM2 and p53 to U1A-positive nuclear bodies associated with the PODs. Exp Cell Res 248: $457-472$

Lain S, Xirodimas D, Lane DP (1999b) Accumulating active p53 in the nucleus by inhibition of nuclear export: a novel strategy to promote the p53 tumor suppressor function. Exp Cell Res 253: $315-324$

Lane DP, Lain S (2002) Therapeutic exploitation of the p53 pathway. Trends Mol Med 8: S38-S42

Lin L, DeMartino GN, Greene WC (1998) Cotranslational biogenesis of NFkappaB p50 by the 26S proteasome. Cell 92: 819-828

Lin L, DeMartino GN, Greene WC (2000) Cotranslational dimerization of the Rel homology domain of NF-kappaB1 generates p50-p105 heterodimers and is required for effective p50 production. $E M B O \mathrm{~J}$ 19: $4712-4722$. 
Lin L, Ghosh SA (1996) Glycine-rich region in NF-kappaB p105 functions as a processing signal for the generation of the p50 subunit. Mol Cell Biol 16: $2248-2254$

Lohrum MA, Ashcroft M, Kubbutat MH, Vousden KH (2000) Identification of a cryptic nucleolar-localization signal in MDM2. Nat Cell Biol 2: $179-181$

Lu X, Burbidge SA, Griffin S, Smith HM (1996) Discordance between accumulated p53 protein level and its transcriptional activity in response to u.v. radiation. Oncogene 13: $413-418$

Middeler G, Zerf K, Jenovai S, Thulig A, Tschodrich-Rotter M, Kubitscheck U, Peters R (1997) The tumor suppressor p53 is subject to both nuclear import and export, and both are fast, energy-dependent and lectininhibited. Oncogene 14: 1407-1417

Midgley CA, Desterro JM, Saville MK, Howard S, Sparks A, Hay RT, Lane DP (2000) An N-terminal p14ARF peptide blocks Mdm2-dependent ubiquitination in vitro and can activate p53 in vivo. Oncogene 19: $2312-2323$

Newlands ES, Rustin GJ, Brampton MH (1996) Phase I trial of elactocin. Br J Cancer 74: $648-649$

Ostrowska H, Wojcik C, Wilk S, Omura S, Kozlowski L, Stoklosa T, Worowski K, Radziwon P (2000) Separation of cathepsin A-like enzyme and the proteasome: evidence that lactacystin/beta-lactone is not a specific inhibitor of the proteasome. Int J Biochem Cell Biol 32: $747-757$

Palombella VJ, Rando OJ, Goldberg AL, Maniatis T (1994) The ubiquitinproteasome pathway is required for processing the NF-kappa B1 precursor protein and the activation of NF-kappa B. Cell 78: $773-785$

Picksley SM, Vojtesek B, Sparks A, Lane DP (1994) Immunochemical analysis of the interaction of p53 with MDM2; fine mapping of the MDM2 binding site on p53 using synthetic peptides. Oncogene 9: $2523-2529$

Pirollo KF, Bouker KB, Chang EH (2000) Does p53 status influence tumor response to anticancer therapies? Anticancer Drugs 11: 419-432

Pochampally R, Fodera B, Chen L, Lu W, Chen J (1999) Activation of an MDM2-specific caspase by p53 in the absence of apoptosis. J Biol Chem 274: $15271-15277$
Rechsteiner M, Rogers SW (1996) PEST sequences and regulation by proteolysis. Trends Biochem Sci 21: 267-271

Roberts BJ, Hamelehle KL, Sebolt JS, Leopold WR (1986) In vivo and in vitro anticancer activity of the structurally novel and highly potent antibiotic CI-940 and its hydroxy analog (PD 114,721). Cancer Chemother Pharmacol 16: $95-101$

Roth J, Dobbelstein M, Freedman DA, Shenk T, Levine AJ (1998) Nucleocytoplasmic shuttling of the hdm 2 oncoprotein regulates the levels of the p53 protein via a pathway used by the human immunodeficiency virus rev protein. $E M B O J$ 17: $554-564$

Smart P, Lane EB, Lane DP, Midgley C, Vojtesek B, Lain S (1999) Effects on normal fibroblasts and neuroblastoma cells of the activation of the p53 response by the nuclear export inhibitor leptomycin B. Oncogene 18: $7378-7386$.

Soussi T (2000) The p53 tumor suppressor gene: from molecular biology to clinical investigation. Ann NY Acad Sci 910: 121-137

Stephen CW, Helminen P, Lane DP (1995) Characterisation of epitopes on human p53 using phage-displayed peptide libraries: insights into antibody-peptide interactions. J Mol Biol 248: 58-78

Stommel JM, Marchenko ND, Jimenez GS, Moll UM, Hope TJ, Wahl GM (1999) A leucine-rich nuclear export signal in the p53 tetramerization domain: regulation of subcellular localization and p53 activity by NES masking. EMBO J 18: $1660-1672$

Tao W, Levine AJ (1999) Nucleocytoplasmic shuttling of oncoprotein $\mathrm{Hdm} 2$ is required for $\mathrm{Hdm} 2$-mediated degradation of p53. Proc Natl Acad Sci USA 96: $3077-3080$

Vousden KH (2002) Activation of the p53 tumor suppressor protein. Biochim Biophys Acta 1602: 47 - 59

Xirodimas D, Saville MK, Edling C, Lane DP, Laín S (2001a) Different effects of p14ARF on the levels of ubiquitinated p53 and Mdm2 in vivo. Oncogene 20: $4972-4983$.

Xirodimas DP, Stephen CW, Lane DP (2001b) Cocompartmentalization of p53 and $\mathrm{Mdm} 2$ is a major determinant for Mdm2-mediated degradation of p53. Exp Cell Res 270: 66-77.

Zhang Y, Xiong Y (2001) A p53 amino-terminal nuclear export signal inhibited by DNA damage-induced phosphorylation. Science 292: $1910-1915$. 